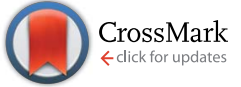

Cite this: RSC Adv., 2017, 7, 16057

Received 6th February 2017

Accepted 7th March 2017

DOI: $10.1039 / \mathrm{c} 7 \mathrm{ra01524k}$

rsc.li/rsc-advances

\section{Impacts of inorganic draw solutes on the performance of thin-film composite forward osmosis membrane in a microfiltration assisted anaerobic osmotic membrane bioreactor $\dagger$}

\begin{abstract}
Taozhan Hu, Xinhua Wang, ${ }^{*}$ Chen Wang, Xiufen $\mathrm{Li}^{\star}$ and Yueping Ren
The influences of inorganic draw solutes on the performance of the thin-film composite forward osmosis (TFC-FO) membrane in microfiltration (MF) assisted anaerobic osmotic membrane bioreactors (AnMFOMBRs) were investigated in this study. The results indicated that compared to sodium chloride ( $\mathrm{NaCl})$ at the same osmotic pressure, magnesium chloride $\left(\mathrm{MgCl}_{2}\right)$ led to a higher flux decline of the TFC-FO membrane, induced by more severe membrane fouling. In addition, the $\mathrm{NaCl}$ and $\mathrm{MgCl}_{2}$ had no impacts on the rejection for organic matters by the TFC-FO membrane. However, the $\mathrm{NH}_{4}{ }^{+}-\mathrm{N}$ rejection of TFC-FO membrane was neglected in the AnMF-OMBR with $\mathrm{NaCl}$ as draw solute, while it was enhanced to a range of $57.5-87.6 \%$ for the draw solute $\mathrm{MgCl}_{2}$. The different $\mathrm{NH}_{4}{ }^{+}-\mathrm{N}$ rejection and membrane fouling of TFC-FO membrane with draw solutes $\mathrm{NaCl}$ and $\mathrm{MgCl}_{2}$ could be attributed to the Donnan potential. As for $\mathrm{NaCl}$, more $\mathrm{Na}^{+}$diffused into the mixed liquor resulting in $\mathrm{NH}_{4}{ }^{+}-\mathrm{N}$ passing through the TFC-FO membrane to the draw solution for keeping a charge balance. With regard to $\mathrm{MgCl}_{2}, \mathrm{more}^{-}$ passing through the $\mathrm{FO}$ membrane to the mixed liquor led to an accumulation of $\mathrm{NH}_{4}{ }^{+}-\mathrm{N}$ in the reactor. Moreover, $\mathrm{Mg}^{2+}$ passing from the draw solution to the mixed liquor enhanced the biofouling on the active layer of the FO membrane, and in the meanwhile more anions passing to the draw solution aggravated the inorganic fouling of the support layer.
\end{abstract}

\section{Introduction}

Recently, a novel concept of an anaerobic osmotic membrane bioreactor (AnOMBR) has been proposed for treating lowstrength wastewater. ${ }^{1-3}$ In the AnOMBR, a forward osmosis (FO) membrane was applied to retain the anaerobic biomass instead of the microfiltration (MF) membrane commonly used in traditional anaerobic membrane bioreactors (AnMBRs). Compared to the MF membrane, the FO membrane has a better retention for organic matter, especially low molecular weight substances, nitrogen and phosphorus, which cannot be retained by the MF membrane. In addition, the fouling of the FO membrane is lower when applying osmotic pressure instead of hydraulic pressure as the driving force and operating at mild flux conditions..$^{4-6}$ Based on the above advantages of the FO membrane over the MF membrane, AnOMBRs have better contaminant removal and effluent water quality than conventional AnMBRs. ${ }^{1-3}$ Nevertheless, there are still some drawbacks

Jiangsu Key Laboratory of Anaerobic Biotechnology, School of Environmental and Civil Engineering, Jiangnan University, Wuxi 214122, P. R. China. E-mail: xhwang@ jiangnan.edu.cn; xfli@jiangnan.edu.cn; Tel: +86-510-85326516

$\dagger$ Electronic supplementary information (ESI) available. See DOI: 10.1039/c7ra01524k associated with the AnOMBRs such as the salinity build-up and the destruction of the FO membrane.

Salt accumulation is a common phenomenon in osmotic membrane bioreactors (OMBRs) owing to the high rejection of FO membrane for solutes and the reverse solutes transport from draw solution. ${ }^{7-15}$ The high salinity environment in OMBRs resulted from salt accumulation not only causes a reduction of water flux but also affects the microbial activity. ${ }^{7-15}$ The same problems induced by the salinity build-up have also been observed in the studies on AnOMBRs. ${ }^{1,2}$ In the AnOMBRs, salt accumulation was commonly alleviated by periodical supernatant discharge when the salinity reached to about $20 \mathrm{mS} \mathrm{cm}^{-1}$.,2 $^{1,2}$ However, this easy controlling method can not avoid the increase of salinity in one cycle of AnOMBRs. In this case, Wang et al. ${ }^{16}$ developed a novel MF-assisted AnOMBR (AnMF-OMBR) for controlling salt accumulation by discharging the solutes from the MF membrane. ${ }^{16}$ The results demonstrated that the salinity was effectively controlled in a low range of 2.5-4.0 mS $\mathrm{cm}^{-1}$, which enabled the AnMF-OMBR achieve a long-term continuous operation and a higher methane production.

Previous studies on the AnOMBRs also indicated the cellulose triacetate (CTA) FO membrane with a low tolerance to both the high temperature and the biological degradation, hence the unstability of CTA membrane was difficult to keep a long time 
continuous operation. ${ }^{1}$ Apart from the CTA-FO membrane, thin film composite polyamide (TFC) membrane is another commercial FO membrane commonly used in the FO process. ${ }^{7,17}$ Compared with the CTA-FO membrane, TFC-FO membrane has higher water flux, lower reverse salt transport and better resistance to hydrolysis and biological degradation. ${ }^{18,19}$ Based on these facts, application of the TFC-FO membrane instead of the CTAFO membrane might be a feasible method for preventing the FO membrane from hydrolysis and biological degradation in the AnOMBRs. Until now, there are no studies on the AnOMBRs used the TFC-FO membrane.

Draw solution is a significant part of FO process because it can significantly affect the performance of the FO membrane. ${ }^{20-24}$ According to previous studies, inorganic salts especially $\mathrm{NaCl}$ and $\mathrm{MgCl}_{2}$ were the most commonly used draw solutes in OMBR studies. ${ }^{4,5,25,26}$ Thus, the objective of this study is to evaluate the performance of TFC-FO membrane in the AnMF-OMBR with the draw solutes of $\mathrm{NaCl}$ and $\mathrm{MgCl}_{2}$. This study may provide a new insight into the impacts of inorganic draw solutes on the performance of FO membrane and thus enhancing their applications in OMBRs for wastewater treatment.

\section{Materials and methods}

\subsection{Experimental set-up}

In this study, two identical laboratory-scale AnMF-OMBRs were operated in parallel. As shown in Fig. 1, the effective volume of each reactor was $4.98 \mathrm{~L}$, and both an FO and an MF modules (each with an effective area of $0.025 \mathrm{~m}^{2}$ ) were immersed in the anaerobic sludge. The MF membrane (polyvinylidene fluoride (PVDF), Zizheng Environment Inc., China) with a mean pore size of $0.20 \mu \mathrm{m}$ was operated under the mode of stable flux, and its water flux was controlled by a peristaltic pump. The TFC-FO membrane (supplied by Hydration Technologies Inc.) had an orientation of active layer facing the mixed liquors. Produced biogas was recycled with a recirculation rate of $2 \mathrm{~L} \mathrm{~min}^{-1}$ for alleviating the membrane fouling and mixing the anaerobic biomass.

The reactors were operated with the same operating conditions except for the draw solute. One reactor applied $\mathrm{NaCl}$ as the draw solute (called as NaCl-reactor), while $\mathrm{MgCl}_{2}$ was used in the other one (called as $\mathrm{MgCl}_{2}$-reactor). In order to keep the

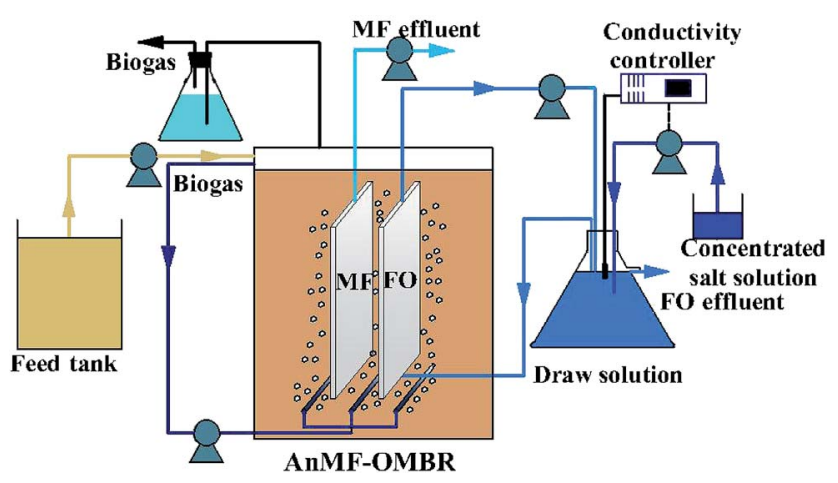

Fig. 1 Schematic diagram of the AnMF-OMBR system. draw solution at the same osmotic pressure (calculated by http://www.lenntech.com), the concentrations of $\mathrm{NaCl}$ and $\mathrm{MgCl}_{2}$ solutions were kept at 0.5 and $0.36 \mathrm{M}$, respectively. The salinity of the draw solutions was kept stable through a conductivity controller equipped with $5 \mathrm{M} \mathrm{NaCl}$ and $3.6 \mathrm{M}$ $\mathrm{MgCl}_{2}$ solutions, respectively. The draw solutions were circulated with a flow rate of $0.4 \mathrm{~L} \mathrm{~min}^{-1}$ in both reactors. Each reactor was operated at the temperature of $25 \pm 0.5{ }^{\circ} \mathrm{C}$ and at the sludge retention time (SRT) of 90 days. The hydraulic retention time (HRT) of both reactors (in the range of 12.5-90 h) varied with the flux changes of MF and FO membranes. The synthetic domestic wastewater was used as the influent with the ammonia nitrogen $\left(\mathrm{NH}_{4}{ }^{+}-\mathrm{N}\right)$, chemical oxygen demand (COD), total organic carbon (TOC), total phosphorus (TP) and total nitrogen (TN) concentrations of $29.0 \pm 0.99,366.7 \pm 5.3,152.9$ $\pm 4.8,3.35 \pm 0.16$ and $35.2 \pm 1.3 \mathrm{mg} \mathrm{L}^{-1}$, respectively. The composition of synthetic wastewater has been listed in previous studies. ${ }^{27,28}$ The seeded sludge in both reactors was collected from a local municipal wastewater treatment plant (Taihu Xincheng WWTP, Wuxi, China) after cultivating approximately 60 days at the temperature of $25 \pm 0.5{ }^{\circ} \mathrm{C}$ in a fermentation flask. The initial sludge concentration in both reactors was controlled at about 3.8 and $2.8 \mathrm{~g} \mathrm{~L}^{-1}$ for mixed liquor suspended solids (MLSS) and mixed liquor volatile suspended solids (MLVSS), respectively.

\subsection{Analytical methods}

COD, $\mathrm{NH}_{4}{ }^{+}-\mathrm{N}, \mathrm{TN}, \mathrm{TP}$, MLSS and MLVSS were conducted by the standard methods, ${ }^{29}$ and the TOC was determined by a TOC analyzer (TOC-Vcsh, Shimadzu, Japan). All the above analyses were conducted at least 3 times, and their mean values \pm standard deviations were reported.

The fouled FO membrane modules were collected from both reactors at the end of their operations, and then cut into some pieces for scanning electron microscopy (SEM), confocal laser scanning microscopy (CLSM) and energy diffusive X-ray (EDX) analyses. The specific methods of SEM, EDX and CLSM analyses could be found in previous literature..$^{12,13,17,30}$

\section{Results and discussion}

\subsection{Impacts of draw solutes on water flux and salinity}

Changes of FO flux and the conductivity of the mixed liquors in both reactors are illustrated in Fig. 2 . It could be observed that the salinity was kept at a low level of about $3 \mathrm{~ms} \mathrm{~cm}^{-1}$ in both reactors with the help of MF membrane. Compared with the AnOMBR used $\mathrm{NaCl}$ as the draw solute, ${ }^{1}$ the salinity obtained in this study was about one magnitude lower, which was due to the enhanced salt leakage through the MF membrane., ${ }^{\mathbf{9} 13}$ In fact, if the MF membrane is not applied for discharging solutes, the salinity will be much higher in the NaCl-reactor compared to the $\mathrm{MgCl}_{2}$-reactor owing to the more severe reverse transport of $\mathrm{NaCl}$ compared to $\mathrm{MgCl}_{2} \cdot{ }^{31}$ It could be demonstrated by a larger MF membrane flux (see Fig. S1 $\dagger$ ) needed for discharging solutes from the $\mathrm{NaCl}-$ reactor in order to achieve a similar salinity environment in the $\mathrm{MgCl}_{2}$-reactor. 

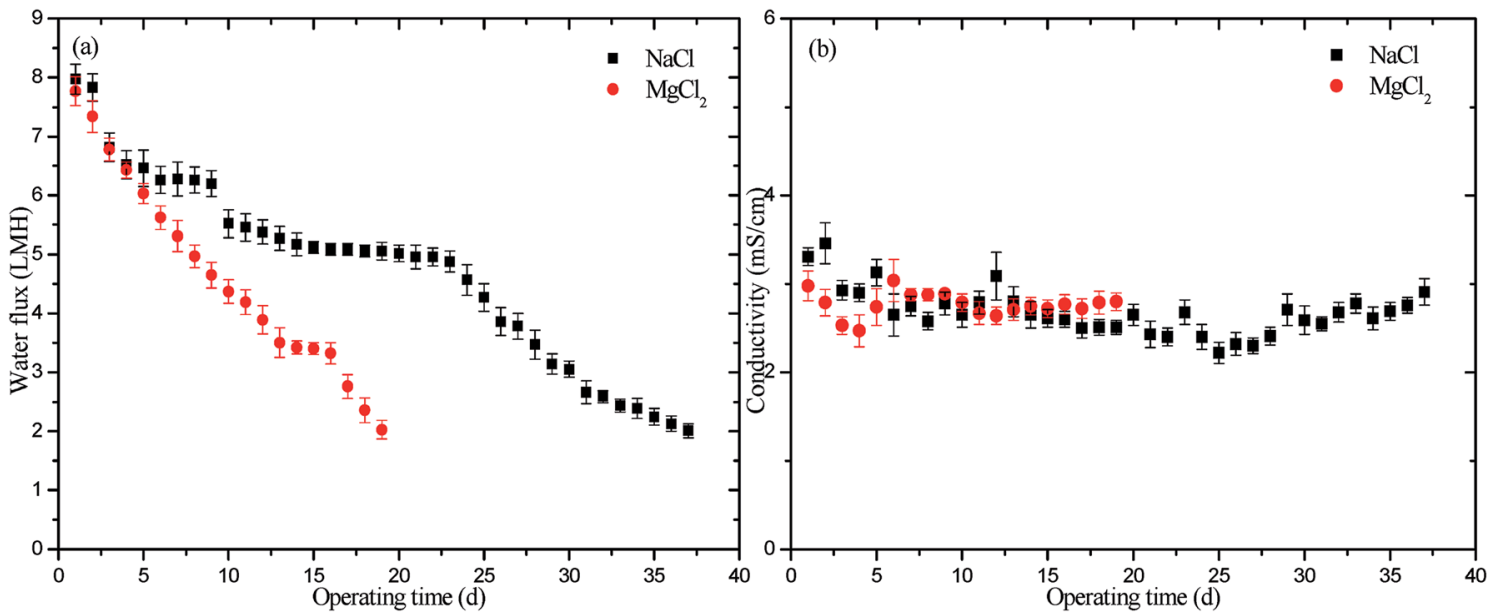

Fig. 2 Variations of FO water flux (a) and the conductivity of the mixed liquors (b) in the AnMF-OMBRs with different draw solutes.

With regard to the changes of the FO membrane flux, there were significant differences between $\mathrm{NaCl}$-reactor and $\mathrm{MgCl}_{2}$ reactor. Compared to the NaCl-reactor, the flux drop of FO membrane was more serious in the $\mathrm{MgCl}_{2}$-reactor. The more severe flux decline directly led to a shorter operating time of the $\mathrm{MgCl}_{2}$-reactor (from 7.77 LMH to 2.06 LMH in 19 days) compared with the NaCl-reactor (from 7.99 LMH to 2.02 LMH in 37 days). According to previous studies, the flux drop of FO membrane in the OMBRs can be attributed to both membrane fouling and salt accumulation..$^{\mathbf{8} 12,13}$ Considering the similar salinity achieved in both reactors, the larger flux drop of FO membrane in the $\mathrm{MgCl}_{2}$ reactor indicated a presence of more serious membrane fouling.

\subsection{Impacts of draw solutes on contaminants rejection}

From Fig. S2, $\uparrow$ regardless of the draw solutes, both reactors achieved a high TOC removal, i.e., the TOC removal efficiencies calculated from the FO permeate were about $98.0 \%$ and $97.7 \%$ for NaCl-reactor and $\mathrm{MgCl}_{2}$-reactor, respectively. The high TOC removal in current study was consistent with conventional AnOMBRs treating low-strength wastewater., ${ }^{\mathbf{1 , 2}}$ However, compared to the COD concentration in sludge supernatant within the range of 100 to $250 \mathrm{mg} \mathrm{L}^{-1}$ in AnOMBRs, ${ }^{1,2}$ it was lower and more stable in the AnMF-OMBR owing to part of COD passing through MF membrane.

As shown in Fig. 3, $\mathrm{NH}_{4}{ }^{+}-\mathrm{N}$ concentrations in sludge supernatant, MF and FO permeates accounted for more than $90 \%$ of TN concentrations in both reactors due to the activity of anaerobes in the hydrolysis phase, which was in agreement with previous researches on the AnOMBRs. ${ }^{\mathbf{1 , 2}}$ Thus, we just focused on the variations of $\mathrm{NH}_{4}{ }^{+}-\mathrm{N}$ concentrations in both reactors. It could be found from Fig. 3 that different draw solutes exhibited much different $\mathrm{NH}_{4}{ }^{+}-\mathrm{N}$ rejection of TFC-FO membrane. When $\mathrm{NaCl}$ was used as the draw solute, the $\mathrm{NH}_{4}{ }^{+}-\mathrm{N}$ concentration in the $\mathrm{FO}$ permeate was much larger than that in the sludge supernatant, indicating that the TFC-FO membrane did not have any $\mathrm{NH}_{4}{ }^{+}-\mathrm{N}$ rejection even though the diffusion rate of $\mathrm{NH}_{4}{ }^{+}-\mathrm{N}$ larger than the water. It was much different from the CTA-FO membrane with a $\mathrm{NH}_{4}{ }^{+}-\mathrm{N}$ rejection of $62.7-81.2 \%$ in AnOMBRs applied
$\mathrm{NaCl}$ as draw solute., ${ }^{1,2}$ However, the TFC-FO membrane had a $\mathrm{NH}_{4}{ }^{+}-\mathrm{N}$ rejection of about $57.5-87.6 \%$ in the $\mathrm{MgCl}_{2}$-reactor. These results implied that the $\mathrm{NH}_{4}{ }^{+}-\mathrm{N}$ rejection of TFC-FO membrane was significantly influenced by the draw solutes. Owing to the different $\mathrm{NH}_{4}{ }^{+}-\mathrm{N}$ rejection of TFC-FO membranes in both reactors, the $\mathrm{NH}_{4}{ }^{+}-\mathrm{N}$ concentration in the sludge supernatant was dramatically different between the two reactors. With regard to the $\mathrm{NaCl}$-reactor, the $\mathrm{NH}_{4}{ }^{+}-\mathrm{N}$ concentration in the supernatant was less than that in the influent, while it was accumulated in the supernatant in the $\mathrm{MgCl}_{2}$-reactor.

The TP concentration of the FO permeate in both reactors (see Fig. $\mathrm{S} 3 \dagger$ ) was below $0.5 \mathrm{mg} \mathrm{\textrm {L } ^ { - 1 }}$ owing to the excellent rejection of TFC membrane. The similarly high TP removal was also observed in AnOMBRs with the CTA-FO membrane. ${ }^{\mathbf{1 , 2}}$ It is interesting to note that the TP concentration of sludge supernatant in the NaCl-reactor was less compared to the $\mathrm{MgCl}_{2}$ reactor. As discussed in Section 3.1, in order to maintain a stable salinity in the AnMF-OMBR, the water flux of MF membrane was larger in the NaCl-reactor owing to the higher reverse salt transport of $\mathrm{NaCl}$. Thus, the lower TP concentration of sludge supernatant in the NaCl-reactor could be attributed to the larger flux of MF membrane (see Fig. S1 $\dagger$ ) based on the fact that partly TP can pass through the MF membrane.

\subsection{Impacts of draw solutes on membrane fouling}

In order to explain the impacts of inorganic draw solutes on FO membrane fouling, the membrane fouling behaviors in both reactors were further analyzed. From Fig. 4, membrane fouling could be clearly observed on both the active layer (AL) and support layer (SL) of FO membranes after the operation of both reactors. However, there were significant differences in the morphology of the AL and SL between NaCl-reactor and $\mathrm{MgCl}_{2}$ reactor. From EDX results (Fig. S4†), there were no significant differences in composition of elements on the fouled FO membranes in both reactors except for the existence of $\mathrm{Mg}$ in the $\mathrm{MgCl}_{2}$-reactor. In addition, it could be observed from Fig. 5 that the biofoulants almost could not be detected in the SL of the fouled FO membranes in both reactors, which was consisted 

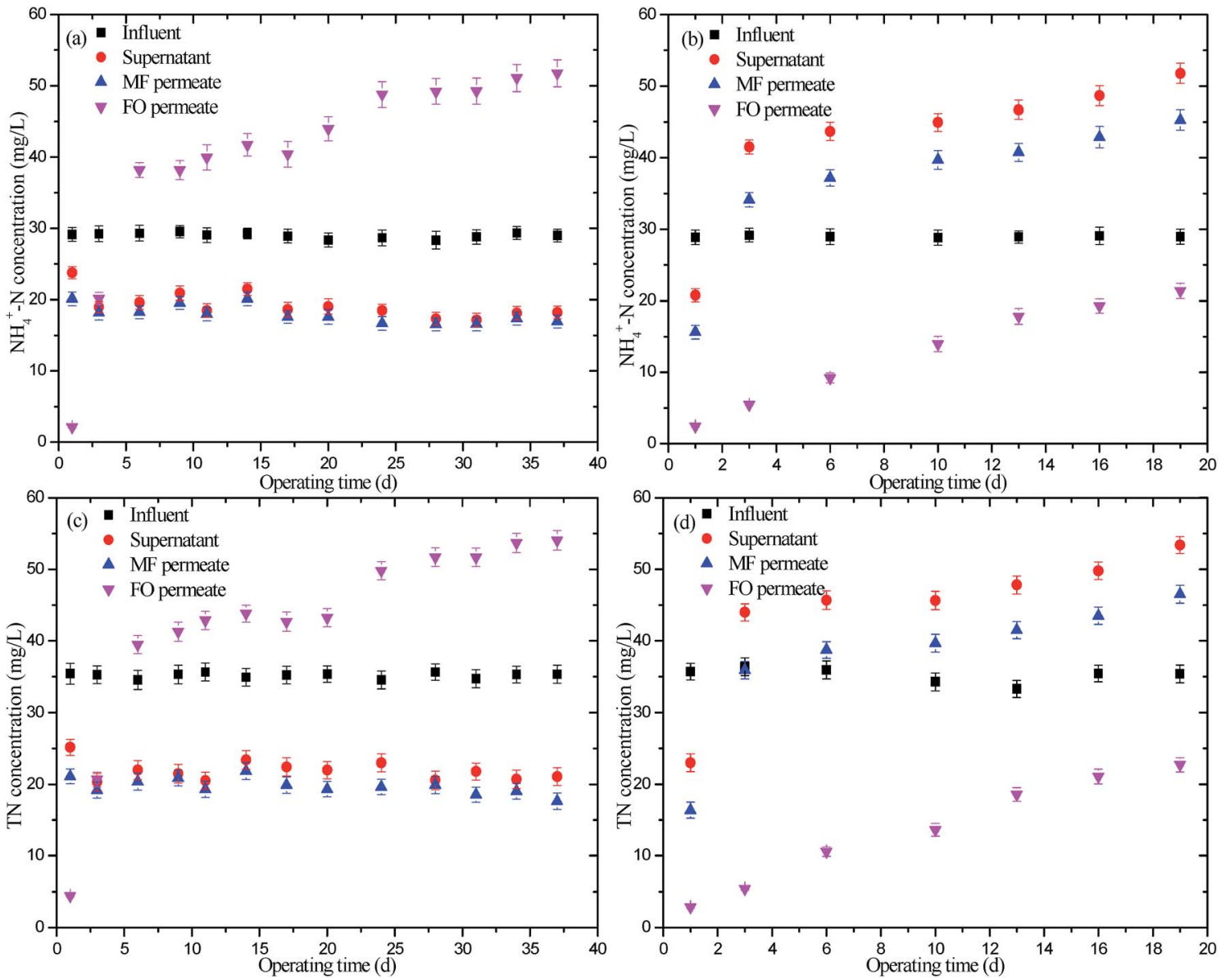

Fig. 3 Variations of $\mathrm{NH}_{4}^{+}-\mathrm{N}$ and $\mathrm{TN}$ concentrations in the influent, sludge supernatant, $\mathrm{MF}$ and $\mathrm{FO}$ permeates. (a) and (b) $\mathrm{NH}_{4}{ }^{+}-\mathrm{N}$ concentrations in $\mathrm{NaCl}$-reactor and $\mathrm{MgCl}_{2}$-reactor, respectively; (c) and (d) $\mathrm{TN}$ concentrations in $\mathrm{NaCl}$-reactor and $\mathrm{MgCl}_{2}$-reactor, respectively.
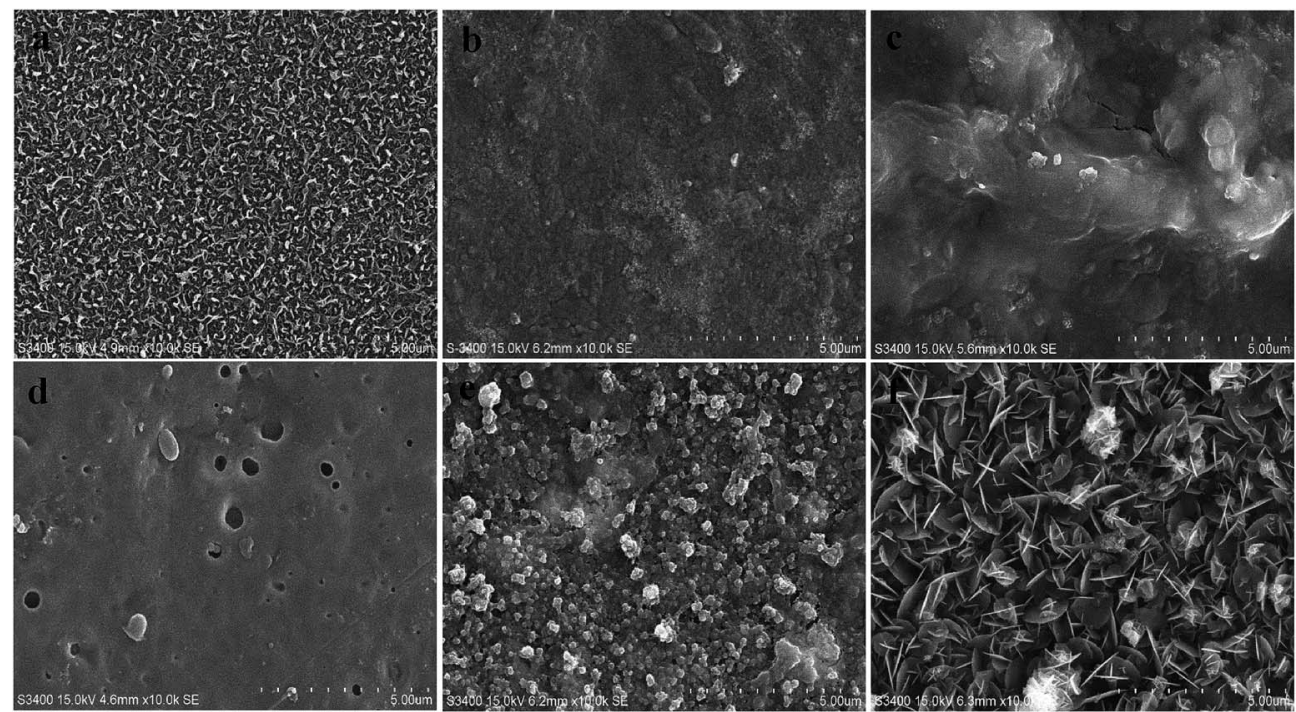

Fig. 4 SEM images of TFC FO membranes. (a) AL of the virgin FO membrane; (b) AL of the fouled FO membrane in the $\mathrm{NaCl}$-reactor; (c) AL of the fouled FO membrane in the $\mathrm{MgCl}_{2}$-reactor; (d) SL of the virgin FO membrane; (e) SL of the fouled FO membrane in the NaCl-reactor; (f) SL of the fouled $\mathrm{FO}$ membrane in the $\mathrm{MgCl}_{2}$-reactor. 

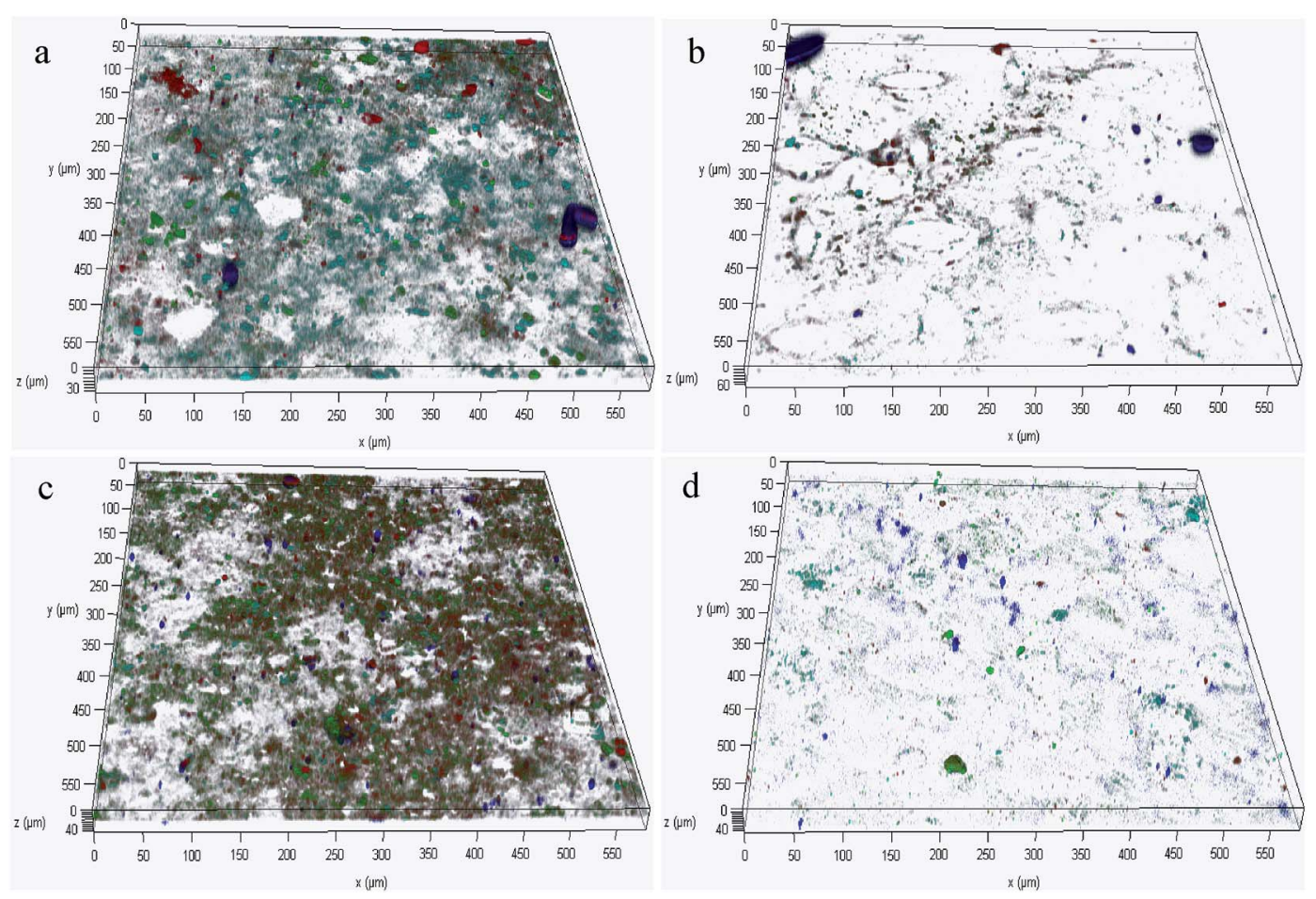

Fig. 5 Integrated CLSM images of polysaccharides, proteins and total cells in the FO biofouling layer. (a) and (b) AL and SL of the fouled FO membrane in the $\mathrm{NaCl}$-reactor, respectively; (c) and (d) $\mathrm{AL}$ and $\mathrm{SL}$ of the fouled $\mathrm{FO}$ membrane in the $\mathrm{MgCl}_{2}$-reactor, respectively.

with the EDX results (no element of N) of the SL of fouled FO membranes, while the biofouling was more severe in the $\mathrm{AL}$ of FO membranes in both reactors. It might be implied that the inorganic fouling was the major fouling in the SL while the biofouling played a significant role in the AL fouling of the AnOMBRs applied inorganic salts as the draw solutes. This phenomenon of different types of foulants in AL and SL might be attributed to the AL facing with the activated sludge full of biofoulants and the SL contacting with the inorganic draw solutions. Moreover, compared with the fouling layer on the $\mathrm{AL}$ in the $\mathrm{NaCl}$-reactor, it was much thicker in the $\mathrm{MgCl}_{2}$-reactor (40 versus $30 \mu \mathrm{m})$. It indicated that more serious biofouling existed on the $\mathrm{AL}$ when $\mathrm{MgCl}_{2}$ was used as draw solute, which might be due to the presence of $\mathrm{Mg}^{2+}$ on the $\mathrm{AL}$ of $\mathrm{FO}$ membrane in the $\mathrm{MgCl}_{2}$-reactor based on the fact that $\mathrm{Ca}^{2+}$ and $\mathrm{Mg}^{2+}$ can enhance the biofouling due to their cationic bridges with extracellular polymeric substances (EPS). ${ }^{17,32,33}$ If further analyzing the distributions of polysaccharides, proteins and microorganisms on the AL in both reactors (Fig. S5 $\dagger$ ), it could be found that the microorganisms and proteins were much more on the $\mathrm{AL}$ in the $\mathrm{MgCl}_{2}$-reactor, suggesting that $\mathrm{Mg}^{2+}$ was more prone to enhance the deposition of microorganisms and proteins on the surface of FO membrane in the AnOMBRs.

It should be pointed out that compared with the CTA-FO membrane in AnOMBRs with the inorganic draw solute, ${ }^{2}$ the TFC-FO membrane had a more severe fouling in this study based on the fact that the fouling layer of CTA-FO membrane could be easily removed just through the tap water while physical cleaning could not recover the water flux of TFC-FO membrane. However, not like the hydrolysis and biological degradation of CTA-FO membrane in AnOMBRs, there are no damages of TFC-FO membrane in current study. Thus, TFC-FO membrane might be more suitable for the AnOMBRs due to its better resistance to hydrolysis and biological degradation.

\subsection{Implications}

The different inorganic draw solutes showed much different performance of TFC-FO membrane including $\mathrm{NH}_{4}{ }^{+}-\mathrm{N}$ rejection and fouling behaviors in the AnMF-OMBR. It might be explained by the Donnan potential. From previous literature, ${ }^{34-37}$ TFC FO membrane has a good rejection performance of divalent cations but a worse rejection for monovalent ions, which resulted in the existence of Donnan equilibrium in current study. As shown in Fig. 6, when $\mathrm{NaCl}$ was used as the draw solute, $\mathrm{Na}^{+}$and $\mathrm{Cl}^{-}$would diffuse from the draw solution to feed solution due to their high concentrations. Owing to the larger diffusion coefficient of $\mathrm{Na}^{+},{ }^{38-41}$ more $\mathrm{Na}^{+}$diffused into feed solution and thus resulting in a charge imbalance between both sides, which eventually led to more cations diffused from feed solution to draw solution for keeping charge at a balance level. Considering the excellent rejection of TFC membrane for divalent ions, $\mathrm{NH}_{4}{ }^{+}-\mathrm{N}$ in the mixed liquor would pass through the membrane to the draw solution. Thus, the larger $\mathrm{NH}_{4}{ }^{+}-\mathrm{N}$ concentration in the draw solution occurred in the AnMFOMBR with $\mathrm{NaCl}$ as draw solute. However, when the draw solute was changed into $\mathrm{MgCl}_{2}$, the diffusion rate of $\mathrm{Mg}^{2+}$ was lower than $\mathrm{Cl}^{-}$due to the high rejection of TFC membrane for $\mathrm{Mg}^{2+} .38$ In this case, more $\mathrm{Cl}^{-}$passed through the TFC membrane to the 

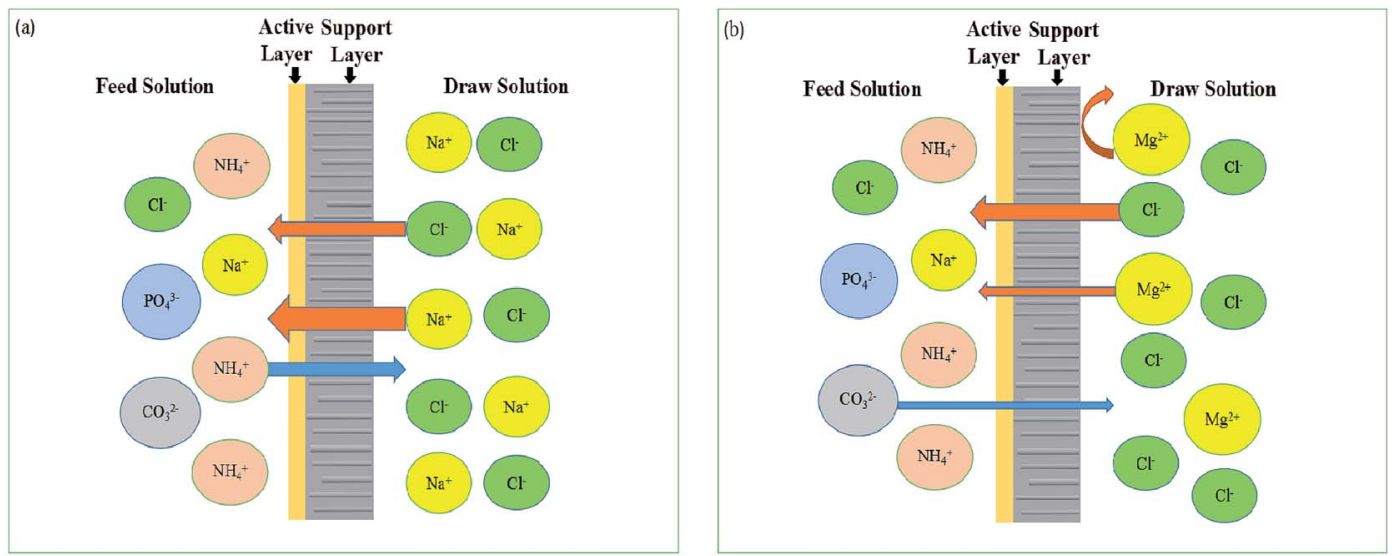

Fig. 6 Schematic diagram of Donnan equilibrium in the TFC FO membrane used $\mathrm{NaCl}$ (a) and $\mathrm{MgCl}_{2}$ (b) as the draw solutes.

mixed liquor, which resulted in not cations but anions prone to permeate to the draw solution. It finally led to an accumulation of $\mathrm{NH}_{4}{ }^{+}-\mathrm{N}$ in the mixed liquor and a decrease in the draw solution. Furthermore, $\mathrm{Mg}^{2+}$ passed to the mixed liquor enhanced the biofouling in $\mathrm{AL}$, and in the meanwhile more anions through the FO membrane to the draw solution aggravated the inorganic fouling of SL.

\section{Conclusion}

In the AnMF-OMBR, the TFC-FO membrane had excellent rejections for organic matters and phosphorus regardless of the applied inorganic draw solutes. However, owing to the Donnan equilibrium, the draw solutes of $\mathrm{NaCl}$ and $\mathrm{MgCl}_{2}$ resulted in significantly different performance of TFC-FO membrane on the $\mathrm{NH}_{4}{ }^{+}-\mathrm{N}$ rejection and membrane fouling in the AnMF-OMBR. When $\mathrm{NaCl}$ was used as the draw solute, the TFC-FO membrane did not have any $\mathrm{NH}_{4}{ }^{+}-\mathrm{N}$ rejection in the AnMF-OMBR, while the $\mathrm{NH}_{4}{ }^{+}-\mathrm{N}$ rejection of TFC-FO membrane was enhanced to a range of $57.5-87.6 \%$ with the draw solute of $\mathrm{MgCl}_{2}$. However, compared to $\mathrm{NaCl}, \mathrm{MgCl}_{2}$ led to a more severe flux drop of TFC membrane, which could be attributed to the $\mathrm{Mg}^{2+}$-enhanced biofouling and inorganic fouling in the AL and SL, respectively.

\section{Acknowledgements}

This work was supported by the National Natural Science Foundation of China [grant number 51578265]; the Fundamental Research Funds for the Central Universities [grant number JUSRP 51728A]; and Jiangsu Cooperative Innovation Center of Technology and Material of Water Treatment.

\section{References}

1 L. Chen, Y. S. Gu, C. Q. Cao, J. Zhang, J. W. Ng and C. Y. Tang, Water Res., 2014, 50, 114-123.

2 Y. S. Gu, L. Chen, J. W. Ng, C. Lee, V. W. C. Chang and C. Y. Tang, J. Membr. Sci., 2015, 490, 197-208.

3 M. K. Y. Tang and H. Y. Ng, Water Sci. Technol., 2014, 69, 2036-2042.
4 K. Lutchmiah, A. R. D. Verliefd, K. Roest, L. C. Rietveld and E. R. Cornelissen, Water Res., 2014, 58, 179-197.

5 X. H. Wang, V. W. C. Chang and C. Y. Y. Tang, J. Membr. Sci., 2016, 504, 113-132.

6 A. Zirehpour, A. Rahimpour, S. Khoshlhal, M. D. Firouzjaei and A. A. Ghoreyshi, RSC Adv., 2016, 6, 70174-70185.

7 A. J. Zhou, H. Y. Luo, Q. Wang, L. Chen, T. C. Zhang and T. Tao, RSC Adv., 2015, 5, 15359-15365.

8 A. Achilli, T. Y. Cath, E. A. Marchand and A. E. Childress, Desalination, 2009, 239, 10-21.

9 R. W. Holloway, J. Ragnery, L. D. Nghiem and T. Y. Cath, Environ. Sci. Technol., 2014, 48, 10859-10868.

10 W. C. L. Lay, Q. Y. Zhang, J. S. Zhang, D. McDougald, C. Y. Tang, R. Wang, Y. Liu and A. G. Fane, Desalination, 2011, 283, 123-130.

11 G. L. Qiu and Y. P. Ting, Bioresour. Technol., 2013, 150, 287297.

12 X. H. Wang, Y. Chen, B. Yuan, X. F. Li and Y. P. Ren, Bioresour. Technol., 2014, 161, 340-347.

13 X. H. Wang, B. Yuan, Y. Chen, X. F. Li and Y. P. Ren, Bioresour. Technol., 2014, 167, 116-123.

14 J. M. Liu, X. H. Wang, Z. W. Wang, Y. Q. Lu, X. F. Li and Y. P. Ren, Water Res., 2017, 110, 74-82.

15 X. H. Wang, Y. X. Zhao, X. F. Li and Y. P. Ren, Chem. Eng. J., 2017, 313, 171-178.

16 X. H. Wang, C. Wang, C. Y. Y. Tang, T. Z. Hu, X. F. Li and Y. P. Ren, J. Membr. Sci., 2017, 527, 1-7.

17 X. H. Wang, Y. X. Zhao, B. Yuan, Z. W. Wang, X. F. Li and Y. P. Ren, Bioresour. Technol., 2016, 202, 50-58.

18 G. M. Geise, H. S. Lee, D. J. Miller, B. D. Freeman, J. E. McGrath and D. R. Paul, J. Polym. Sci., Part B: Polym. Phys., 2010, 48, 1685-1718.

19 Y. S. Gu, Y. N. Wang, J. Wei and C. Y. Y. Tang, Water Res., 2013, 47, 1867-1874.

20 W. H. Luo, F. I. Hai, W. E. Price and L. D. Nghiem, Sep. Purif. Technol., 2015, 145, 56-62.

21 W. H. Luo, F. I. Hai, W. E. Price, W. S. Guo, H. H. Ngo, K. Yamamoto and L. D. Nghiem, Bioresour. Technol., 2014, 167, 539-546. 
22 Q. H. She, X. Jin, Q. H. Li and C. Y. Tang, Water Res., 2012, 46, 2478-2486.

23 Y. N. Wang, E. Järvelä, J. Wei, M. Zhang, H. Kyllönen, R. Wang and C. Y. Tang, Desalination, 2016, 377, 1-10.

24 S. Zou, Y. S. Gu, D. Z. Xiao and C. Y. Tang, J. Membr. Sci., 2011, 366, 356-362.

25 Q. C. Ge, M. M. Ling and T. S. Chuang, J. Membr. Sci., 2013, 442, 225-237.

26 S. F. Zhao, L. Zou, C. Y. Tang and D. Mulcahy, J. Membr. Sci., 2012, 396, 1-21.

27 K. Chen, X. H. Wang, X. F. Li, J. J. Qian and X. L. Xiao, Sep. Purif. Technol., 2011, 82, 148-155.

28 X. H. Wang, J. J. Qian, X. F. Li, K. Chen, Y. P. Ren and Z. Z. Hua, Desalination, 2012, 296, 24-29.

29 APHA, Standard Methods for the Examination of Water and Wastewater, American Public Health Association/American Water Works Association/Water Environment Federation, Washington, DC, 22nd edn, 2012.

30 B. Yuan, X. H. Wang, C. Y. Tang, X. F. Li and G. H. Yu, Water Res., 2015, 75, 188-200.

31 Y. P. Devia, T. Imai, T. Higuchi, A. Kanno, K. Yamamoto, M. Sekine and T. V. Le, J. Water Resour. Prot., 2015, 7, 730740 .
32 Y. H. Mo, K. Xiao, Y. X. Shen and X. Huang, Sep. Purif. Technol., 2011, 82, 121-127.

33 D. L. Hu, Z. Zhou, T. H. Niu, H. J. Wei, W. X. Dou, L. M. Jiang and Y. lv, Sep. Purif. Technol., 2017, 172, 357-365.

34 J. Wei, C. Qiu, C. Y. Y. Tang, R. Wang and A. G. Fane, J. Membr. Sci., 2011, 372, 292-302.

35 N. Y. Yip, A. Tiraferri, W. A. Phillip, J. D. Schiffman and M. Elimelech, Environ. Sci. Technol., 2010, 44, 3812-3818.

36 H. Xie, T. Saito and M. A. Hickner, Langmuir, 2011, 27, 47214727.

37 D. X. Hou, L. Lu and Z. Y. J. Ren, Water Res., 2016, 98, 183189.

38 X. L. Lu, C. Boo, J. Ma and M. Elimelech, Environ. Sci. Technol., 2014, 48, 14369-14376.

39 L. X. Bian, Y. Y. Fang and X. L. Wang, Membranes, 2014, 4, 275-286.

40 B. D. Coday, D. M. Heil, P. Xu and T. Y. Cath, Environ. Sci. Technol., 2013, 47, 2386-2393.

41 Y. H. Li and S. Gregory, Geochim. Cosmochim. Acta, 1974, 38, 703-714. 